\title{
Ethical and Regulatory Issues with Residual Newborn Screening Dried Bloodspots
}

\author{
Erin Rothwell1, Jeffrey R. Botkin² \\ ${ }^{1}$ College of Nursing and Division of Medical Ethics and Humanities, University of Utah, Salt Lake City, UT, USA \\ ${ }^{2}$ Division of Medical Ethics and Humanities, Pediatrics, and Associate Vice President for Research, University of \\ Utah, Salt Lake City, UT, USA \\ Email: erin.rothwell@nurs.utah.edu
}

Received 15 September 2015; accepted 19 October 2015; published 22 October 2015

Copyright (C) 2015 by authors and Scientific Research Publishing Inc.

This work is licensed under the Creative Commons Attribution International License (CC BY).

http://creativecommons.org/licenses/by/4.0/

(c) (†) Open Access

\begin{abstract}
After newborn screening is completed, most states retain leftover dried bloodspots. These dried bloodspots are stored for varying lengths of time among different state newborn screening programs. Dried bloodspots are a unique and valuable resource for the development of new newborn screening tests, quality assurance and biomedical research. Recent changes to the 2014 Newborn Screening Reauthorization Saves Lives Act require explicit parental consent for the retention and use of dried bloodspots in federally funded research. This has raised several ethical and regulatory issues and highlighted the challenges of respecting individual autonomy and public health goals. This article provides an overview of these issues and discusses methods for obtaining parental consent. These issues may be applicable to consent for the storage and use of biospecimens among other settings according to proposed changes to the Common Rule.
\end{abstract}

\section{Keywords}

Residual Dried Blood Spots (DBS), Newborn Screening (NBS), Public Health, Population Research

\section{Introduction}

The Newborn Screening Saves Lives Reauthorization Act of 2014 was signed into law on December 18, 2014. This law renewed federal funding in support of state based newborn screening (NBS) programs. NBS has been recognized as one of the most successful public health programs in the past century [1]. However, the bill includes a new section requiring that federally funded research on residual newborn screening dried bloodspots will be considered human subjects research and must include explicit parental consent. Similarly, the Department of Health and Human Services and fifteen other federal agencies on September 8, 2015 also released a No- 
tice of Proposed Rulemaking that proposed a requirement for consent for the secondary use of biospecimens obtained through clinical care even if they were de-identified [2]. This has generated substantial concern among public health officials who are distressed that explicit parental consent may reduce the number of residual dried blood spots (DBS) available for research and may negatively impact newborn screening participation.

Prior to recent proposed changes in the Common Rule, individuals are "human subjects" if their identity can be readily ascertained by the investigator (45CFR46.102(f)). Accordingly, prior to this amendment, research with de-identified residual DBS was not considered human subjects research and researchers were able to use them without parental consent. Residual DBS have been particularly important for program development and evaluation of existing and new screens, research on rare diseases, and public health research [3] [4]. Furthermore, residual DBS are a unique and valuable resource for public health and population based research because they represent the entire population and as such are free from selection bias [5]. This provision in the bill has created substantial concerns in the newborn screening community. This article will discuss the ethical conflict between respecting individual autonomy and public health goals, and implications of these issues for obtaining parental consent.

\section{Newborn Screening and Residual Dried Blood Spots (DBS)}

Newborn screening enables the early detection and interventions for more than 30 conditions including phenylketonuria (PKU), sickle cell disease, cystic fibrosis, and congenital hypothyroidism. These programs have been highly effective in reducing morbidity from these conditions. NBS is conducted in the newborn nursery by obtaining a blood sample from a heel stick applied to filter paper. A battery of screening tests is performed, and more blood is taken than necessary for these tests in case reanalysis is needed. This approach results in a leftover blood sample for almost every child screened. The leftover blood or the residual dried blood spots (DBS) are stored for variable lengths of time and storage conditions that differ by each of the different state-based NBS programs. Approximately six states store DBS indefinitely, eight states store them for 21 - 30 years, three states store them for 10 - 20 years, and the remaining states store them for 12 months or less [6]. See Graphic 1 [7].

DBS are commonly used for quality assurance purposes for NBS and to improve or evaluate new types of screens to be included on NBS panels. Investigators have also used DBS for other research purposes such as epidemiological research of infectious diseases, childhood leukemia, population based studies of environmental or pharmacological exposures and etiological studies of birth defects and development disabilities [8]-[14]. DNA in residual DBS is stable for long periods of time and is highly useful for genetic epidemiology research. The

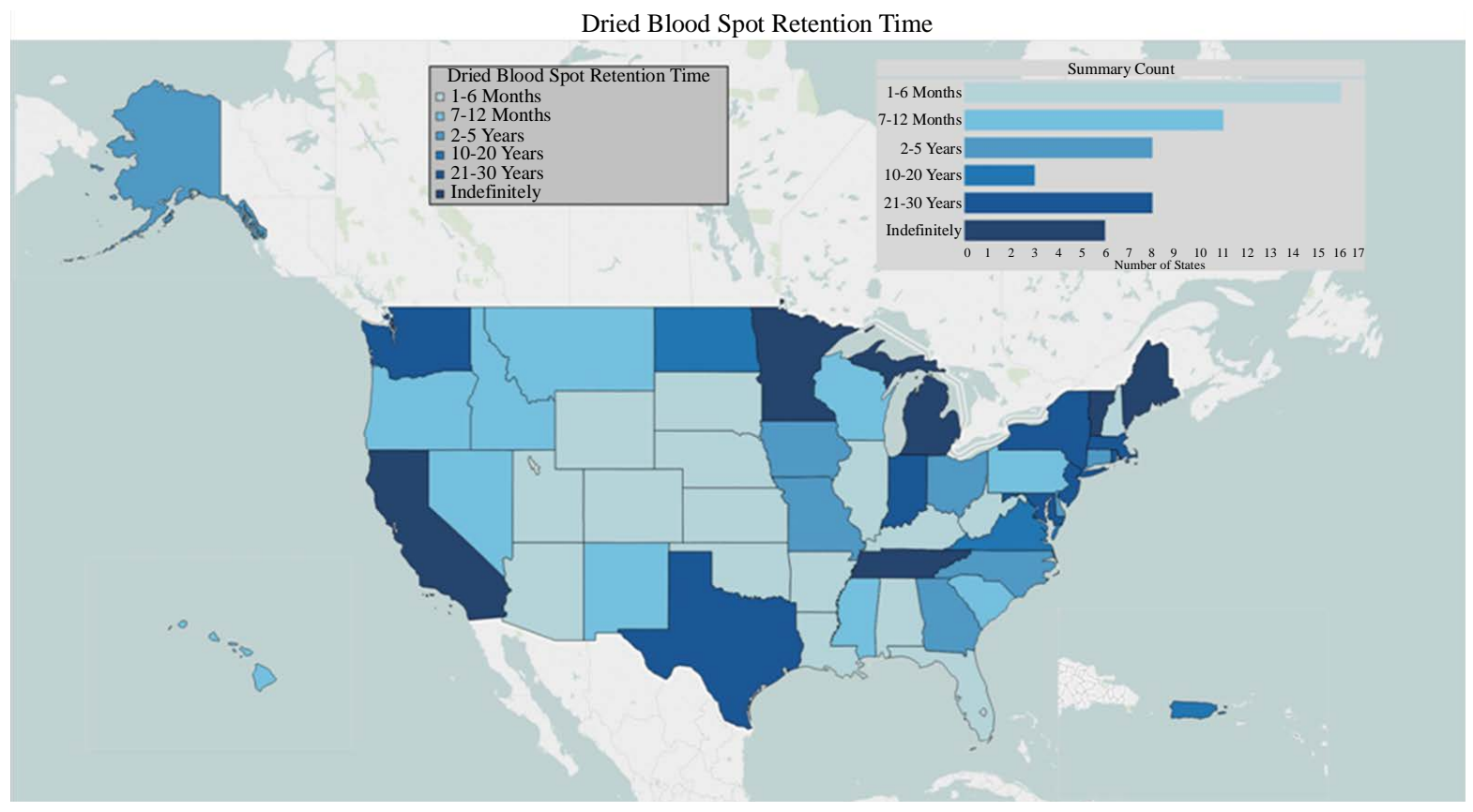

Graphic 1. Dried Blood Spot Retention Time by State. 
vast majority of this research has been done with de-identified DBS. As noted, this type of research has not been considered human subjects research and parental permission has not been required under the regulations prior to the 2014 federal legislation.

Research with DBS is similar to other types of biomedical research using residual clinical samples. For example, most biospecimens are collected during clinical care such as surgery or blood draws [15]. The residual biospecimens are sent to a hospital pathology department or an independent pathology laboratory for processing and diagnosis. After the diagnosis, biospecimens are typically stored in pathology laboratories based on state laws and recommendations by professional organizations such as the College of American Pathologists [16] [17]. These leftover clinical biospecimens, when de-identified, have been used extensively without explicit consent for new testing or treatments specific to the disease and for medical-legal cases [18]. In addition, these biospecimens have been used beyond the disease that the individual received clinical care in other translational and clinical research, biomarker evaluation and drug development research [19]. Biospecimens obtained through clinical care have been especially critical for cancer research because thousands of tumor samples can be collected over time analyzed for a variety of different attributes in various projects as knowledge and technologies evolve [20]. Much of the research with biospecimens is dependent on access to large numbers. However, biospecimens collected in other clinical setting are different than those obtained through newborn screening because most clinical biospecimens are not acquired within a mandated public health program.

In almost all states, newborn screening is a mandatory program for which parental consent is not required. Under the parens patriae doctrine, states are given the authority to screen newborns based on the welfare of the child and benefits to society. This legal doctrine only functions if there is sufficient public trust that the state is appropriately balancing child welfare with respect for parental authority. There are concerns that consent for residual DBS will be confused with the NBS program itself, and that it may generate questions why consent is not required for NBS [21]. Another concern is that many individuals will not want the state health departments to retain any blood sample of a child for any length of time, and thus may decline NBS altogether for their child. Finally, the NBS programs were not created for the retention and use of residual DBS for non-related NBS research and may be outside their legal authority [22]. So while a consent process will defer to parental authority in making decisions about research participation, there are concerns that a consent process will negatively impact pediatric research and may negatively impact these important public health programs themselves.

Two lawsuits in the states of Texas and Minnesota in 2009 resulted from research on de-identified residual DBS without parental consent. The primary argument for the Minnesota lawsuit was based on the premise that secondary research use of DBS without parents' consent violated the states' genetic privacy acts. In the case, Bearder v. State of Minnesota (2009), the lawsuit initially was dismissed in favor of the Minnesota Department of Health, concluding that DBS retention and use did not violate the state's genetic privacy act. In Texas, the lawsuit was based on a constitutional argument that retention violated the 4th amendment as a form of illegal search and seizure. In the case, Beleno v. Texas Dept. of State Health Services (2009), the state ultimately destroyed over 5 million stored DBS. Both programs now involve an informed consent process for parents for future storage and research use of DBS. While the legal theories differed substantially in these two cases, the results indicate both that parents have legitimate concerns about the retention and use of residual DBS without consent and that there are legal bases for objecting to this practice. A larger impact of these lawsuits was the undermining of public trust with the state newborn screening programs).

\section{Education and Consent Approaches}

The new federal amendment raises important questions of how to obtain valid informed consent for residual DBS research and how to implement this practice on a population level. There have been ongoing difficulties for education about NBS itself. Public health departments provide education about NBS primarily through the distribution of brochures. The brochure is often combined with other brochures and materials that women are provided in the hospitals when they give birth. Education around the birth of the child is a hectic time due to recovery from labor and delivery, and meeting the demands of a newborn. Many parents and professionals have argued that education about NBS is more appropriate prior to the birth of a child [23] [24]. However, NBS is not part of prenatal care and despite support by American College of Obstetrics and Gynecology, few prenatal care providers are educating their parents about NBS. These challenges to education are magnified when the goal is to target all women giving birth, that is, 4 million parents per year in the US. 
Our research team has conducted a number of studies on parental attitudes and preferences about the retention and use of residual DBS. In one study, we conducted a 4-part project that involved: a comprehensive analysis of NBS state laws [22]; focus groups with NBS advisory committee members and interviews with NBS program employees [21]; national survey of public attitudes $(n=3855)$ [25] [26]; and ending with a working group of NBS experts to develop policy recommendations [27]. (NIH; R01 HG004970-01) Outcomes of this research provide substantial evidence that parents are supportive of research with DBS but want to be given a choice. Furthermore, this research highlighted the problem of educating parents about NBS and DBS during postpartum care and concerns of NBS professionals that education about DBS may negatively impact NBS participation. A follow-up study then assessed the impact of prenatal education about NBS and the storage and retention of DBS on parental attitudes and choices about NBS. (NIH; R01HD062762). A randomized control trial was conducted in Utah, New York, and California with women who were 32 - 38 weeks pregnant $(N=901)$. The participants were assessed 2 - 4 weeks postnatally about knowledge, attitudes and choice about NBS and DBS. The results demonstrated that participants who received prenatal education about NBS and DBS were more supportive of both NBS and DBS research. The prenatal education also did not negatively impact NBS participation. A publication of these results is pending elsewhere.

This research is consistent within other empirical findings on residual clinical samples, in that, participants are also supportive of research when given a choice. For example, most participants were supportive of future unlimited research on anonymous samples when they were asked [15] [28]. In a study by Chen et al. (2005), more than $85 \%$ of the research participants authorized future unlimited research on anonymous samples if they were asked beforehand [15], and Wendler and Emanuel (2002) found 65.8\% of the sample would want consent for research on identified samples derived from clinical settings [28].

As noted above, some have stated that the NBS programs were not created to retain and use DBS in biomedical research and explicit consent would ensure public trust. While the parens patriae justification works for newborn screening, it does not work for the retention and use of DBS, a practice that does not directly benefit the infants being screened. Parental consent will need to be required for storage and use of DBS but implementing this on a population level will be difficult. In the state of Michigan, where the state health department created the Michigan BioTrust, there is only a 60\% parental consent to allow the samples to be used in research [29]. This low uptake is not primarily from parental refusal but more from the logistical challenges of getting consent at this time in the hospital. Further, some argue that a one-time broad or blanket consent for future, unspecified research with DBS may not constitute adequate consent because it is unknown how the residual DBS will be used in the future [30]. Finally, signatures on consent forms can be easily obtained in many clinical circumstances with limited or no comprehension by individuals signing the form of the issues at hand.

The research evidence clearly demonstrates that participant comprehension of information presented during the consent process is low. A review of clinical informed consent for research between 1961 to 2006 revealed that only 54\% understood the aim of the research; $50 \%$ understood randomization and the risks of the research; $47 \%$ understood the nature of voluntariness; $44 \%$ understand the right to withdrawal; and 57\% understood the benefits of the research [31]. Efforts to improve participant comprehension in the consent process are emerging but identification of best practices or types of informed consent interventions need more research. For example, a systematic review of 54 interventions tested in randomized controlled trials found participant comprehension was improved through multi-media efforts (31\%), enhanced/simplified consent forms (41\%), extended discussions (50\%), and comprehension assessments (33\%) [32]. Current recommendations for promoting participant comprehension during the consent process are the use of simplified consent form and/or multi-media approaches.

To examine the role of simplified paper consent and video education about NBS and DBS, we also conducted a pilot project within a parent randomized control trial (RCT). (The parent RCT is described above and assessed prenatal education about NBS and DBS (NIH; R01HD062762)). The study compared a simplified paper consent form only to a video plus the simplified paper consent form. The results demonstrated improved comprehension on some aspects of study specific details [33]. This intervention will be tested in the State of Michigan and the Michigan BioTrust on participant comprehension and uptake (NIH R01 HD082148-01A1). A specific goal of this research will to address the feasibility of this education on the population level as well as different modalities for promoting participant comprehension about broad consent for future unlimited research with DBS.

\section{Challenges}

DBS are one of the most valuable resources for biospecimen research and has the potential for significant ad- 
vancements in biomedical research because they represent entire population free from selection bias. Also, much of the research with biospecimens is minimal risk research. To date, there have been no reported adverse events from research with DBS. With robust education about storage and research use of DBS, transparency can be maintained with the public. Although much more work needs to be done to identify the best platform for parental consent, there are additional efforts that may need to happen to preserve public trust within these mandatory public health programs through effective education efforts. The timing and frequency of education for a mandatory program is essential. As noted above, participant comprehension about informed consent is low. Multiple methods of consent approaches for the population-level will be need to evaluated to assess not only the feasibility but impact on participant comprehension. It may be more beneficial to focus on educational efforts about newborn screening and residual DBS during prenatal care as well as newborn care. This is also consistent with the research evidence reports that many parents want to receive education about newborn screening during prenatal care and that repetition of information can enhance learning [26].

Within the domain of public health research and respecting individual autonomy, finding a balance will be necessary for research with DBS. Recommendations from the Secretary of Health and Human Services' Advisory Committee on Heritable Disorders in Newborns and Children, also recognize this need to balance between individual privacy and public good. Their recommendations support the retention and use of DBS because they are a valuable resource for the public good [34]. Furthermore, a broader discussion of the role informed consent within population based research and genomics needs to occur. For example, there are questions about when is the appropriate time to require consent for research with biospecimens and that is not necessarily at the time of collection.

\section{Conclusion}

In summary, changes to the regulatory landscape for biospecimen research are not limited to research with residual DBS. Recent proposed changes to the Common Rule require consent for research with prospectively collected biospecimens but it unknown whether these regulatory changes will be adopted and, if so, how they will be implemented. Within the context of NBS programs, the primary goal is to screen infants for early identification of inherited medical conditions so that a timely treatment and intervention can take place. From a public health perspective, missing one child who would benefit from NBS is detrimental to the mission of this program. Finding a way to obtain parental consent for the storage and use of DBS without adversely affecting NBS is necessary. These samples are obtained through a mandatory public health program and not only will parental consent be required but we also have an obligation to ensure comprehension of the consent process. To continue to improve the healthcare of infant and public health, research with DBS will play a critical role.

\section{References}

[1] Prevention, C.F.D.C.A. (2011) Ten Great Public Health Achievements-United States, 2001-2010. Morbidity and Mortality Weekly Report 2011.

[2] Services, D.O.H.A.H. (2015) NPRM for Revisions to the Common Rule. http://www.hhs.gov/ohrp/humansubjects/regulations/nprmhome.html

[3] Olney, R., Moore, C.A., Ojodu, J.A., Lindegren, M.L. and Hannon, W.H. (2008) Storage and Use of Residual Dried Blood Spots from State Newborn Screening Programs. Journal of Pediatrics, 148, 618-622. http://dx.doi.org/10.1016/j.jpeds.2005.12.053

[4] Vasconcelos, G., Kang, M., Pombo-de-Oliveira, M.S., Schiffman, J.D., Lorey, F., Buffler, P. and Wiemels, J.L. (2008) Adenovirus Detection in Guthrie Cards from Paediatric Leukaemia Cases and Controls. British Journal of Cancer, 99, 1668-1672. http://dx.doi.org/10.1038/sj.bjc.6604714

[5] Bayefsky, M., Saylor, K. and Berkman, B. (2015) Parental Consent for Use of Residual Newborn Screening Bloodspots: Respecting Individual Liberty vs Ensuring Public Health. Journal of the American Medical Association, 314, 2122. http://dx.doi.org/10.1001/jama.2015.6175

[6] NewSteps (2015) Dried Blood Spot Retention. https://data.newsteps.org/newsteps-web/reports/profile/dbsRetention.action

[7] NewSteps (2015) Data Retention Profile by State. https://data.newsteps.org/newsteps-web/reports/profile/dataRetention.action

[8] Barbi, M., Sandro, B., Valeria, P., Alberto, T., Carlo, N. and Carlo, B. (1998) Use of Guthrie Cards for the Early Di- 
agnosis of Neonatal Herpes Simplex Virus Disease. The Pediatric Infectious Disease Journal, 17, 251-252. http://dx.doi.org/10.1097/00006454-199803000-00017

[9] Barbi, M., Binda, S. and Caroppo, S. (2006) Diagnosis of Congenital CMV Infection via Dried Blood Spots. Reviews in Medical Virology, 16, 385-392. http://dx.doi.org/10.1002/rmv.517

[10] Chaudhuri, S., Butala, S.J.M., Ball, R.W. and Braniff, C.T. (2009) Pilot Study for Utilization of Dried Blood Spots for Screening of Lead, Mercury and Cadmium in Newborns. Journal of Exposure Science and Environmental Epidemiology, 19, 298-316. http://dx.doi.org/10.1038/jes.2008.19

[11] Burse, V.W., Deguzman, M.R., Korver, M.P., Najam, A.R., Williams, C.C., Hannon, W.H. and Therrell, B.L. (1997) Preliminary Investigation of the Use of Dried-Blood Spots for the Assessment of in Utero Exposure to Environmental Pollutants. Biochemical and Molecular Medicine, 61, 236-239. http://dx.doi.org/10.1006/bmme.1997.2603

[12] Gwinn, M., Pappaioanou, M., George, J.R., Hannon, W.H., Wasser, S.C., Redus, M.A., et al. (1991) Prevalence of HIV Infection in Childbearing Women in the United Statbares: Surveillance Using Newborn Blood Samples. JAMA, 265, 1704-1708. http://dx.doi.org/10.1001/jama.1991.03460130096029

[13] Shaw, G., Zhu, H.P., Lammer, E.J., Yang, W. and Finnell, R.H. (2003) Genetic Variation of Infant Reduced Folate Carrier (A80G) and Risk of Orofacial and Conotruncal Heart Defects. American Journal of Epidemiology, 158, 147152. http://dx.doi.org/10.1093/aje/kwg189

[14] Nelson, K., Grether, J.K., Croen, L.A., Dambrosia, J.M., Dickens, B.F., Jelliffe, L.L., Hansen, R.L. and Phillips, T.M. (2001) Neuropeptides and Neurotrophins in Neonatal Blood of Children with Autism or Mental Retardation. Annals of Neurology, 49, 597-606. http://dx.doi.org/10.1002/ana.1024

[15] Chen, D.T., Rosenstein, D.L., Muthappan, P., Hilsenbeck, S.G., Miller, F.G., Emanuel, E.J. and Wendler, D. (2005) Research with Stored Biological Samples: What Do Research Participants Want? Archives of Internal Medicine, 165, 652-655. http://dx.doi.org/10.1001/archinte.165.6.652

[16] Harty-Golder, B. (2004) Retention and Ownership of Blocks. MLO: Medical Laboratory Observer, $36,37$.

[17] Hakimian, R. and Korn, D. (2004) Ownership and Use of Tissue Specimens for Research. JAMA, 292, 2500-2505. http://dx.doi.org/10.1001/jama.292.20.2500

[18] Dry, S. (2009) Who Owns Diagnostic Tissue Blocks? LabMedicine, 40, 69-73. http://dx.doi.org/10.1309/lm3xp8hbkdsgicjh

[19] Olson, J., Bielinski, S.J., Ryu, E., Winkler, E.M., Takahashi, P.Y., Pathak, J. and Cerhan, J.R. (2014) Biobanks and Personalized Medicine. Clinical Genetics, 86, 50-55. http://dx.doi.org/10.1111/cge.12370

[20] Voduc, D., Kenney, C. and Nielson, T. (2008) Tissue Microarrays in Clinical Oncology. Seminars in Radiation Oncology, 18, 89-97. http://dx.doi.org/10.1016/j.semradonc.2007.10.006

[21] Rothwell, E., Anderson, R.A., Burbank, M.J., Goldenberg, A.J., Lewis, M.H., Stark, L.A., et al. (2011) Concerns of Newborn Screening Advisory Committee Members Regarding Storage and Use of Residual Newborn Screening Bloodspots. American Journal of Public Health, 101, 2111-2116. http://dx.doi.org/10.2105/AJPH.2010.200485

[22] Lewis, M.H., Goldenberg, A., Anderson, R., Rothwell, E. and Botkin, J. (2011) State Laws Regarding the Retention and Use of Residual Newborn Screening Blood Samples. Pediatrics, 127, 703-712. http://dx.doi.org/10.1542/peds.2010-1468

[23] Rothwell, E., Clark, L., Anderson, R. and Botkin, J.R. (2012) Residual Newborn Screening Samples for Research: Parental Information Needs for Decision-Making. Journal for Specialists in Pediatric Nursing, 18, 115-122.

[24] Rothwell, E., Anderson, R. and Botkin, J.R. (2010) Policy Issues and Stakeholder Concerns Regarding the Storage and Use of Residual Newborn Dried Blood Samples for Research. Policy, Politics, and Nursing Practice, 11, 5-12. http://dx.doi.org/10.1177/1527154410365563

[25] Botkin, J.R., Rothwell, E., Anderson, R., Stark, L.A. and Mitchell, J. (2014) Public Attitudes Regarding the Use of Electronic Health Information and Residual Clinical Tissues for Research. Journal of Community Genetics, 5, 205-213.

[26] Rothwell, E., Anderson, R., Goldenberg, A., Lewis, M.H., Stark, L., Burbank, M., et al. (2012) Assessing Public Attitudes on the Retention and Use of Residual Newborn Screening Blood Samples: A Focus Group Study. Social Science \& Medicine, 74, 1305-1309. http://dx.doi.org/10.1016/j.socscimed.2011.12.047

[27] Botkin, J.R., Goldenberg, A.J., Rothwell, E., Anderson, R.A. and Lewis, M.H. (2013) Policy Guidance for the Retention and Research Use of Residual Newborn Screening Bloodspots. Pediatrics, 131, 120-127. http://dx.doi.org/10.1542/peds.2012-0852

[28] Wendler, D. and Emanuel, E.J. (2002) The Debate Over Research on Stored Biological Samples: What Do Sources Think? Archives of Internal Medicine, 162, 1457-1462. http://dx.doi.org/10.1001/archinte.162.13.1457

[29] Health, M.B.F. (2013) Michigan BioTrust for Health: 2013 Annual Report. 
[30] Caulfield, T., Upshur, R. and Daar, A. (2003) DNA Databanks and Consent: A Suggested Policy Option Involving an Authorization Model. BMS Ethics, 4, 1. http://dx.doi.org/10.1186/1472-6939-4-1

[31] Falagas, M., Korbila, I.P., Giannopoulou, K.P., Kondilis, B.K. and Peppas, G. (2009) Informed Consent: How Much and What Do Patients Understand? The American Journal of Surgery, 198, 420-435. http://dx.doi.org/10.1016/j.amjsurg.2009.02.010

[32] Nishimura, A., Carey, J., Erwin, P.J., Tilburt, J.C., Murad, M.H. and McCormick, J.B. (2013) Improving Understanding in the Research Informed Consent Process: A Systematic Review of 54 Interventions Tested in Randomized Control Trials. BMC Medical Ethics, 14, 28. http://dx.doi.org/10.1186/1472-6939-14-28

[33] Rothwell, E., Wong, B., Rose, N.C., Anderson, R., Fedor, B., Stark, L.A. and Botkin, J.R. (2014) A Randomized Contolled Trial of an Electronic Informed Consent Process. Journal of Empirical Research on Human Research Ethics, 9, 1-7. http://dx.doi.org/10.1177/1556264614552627

[34] Therrell, B.L., Hannon, W.H., Bailey, D.B., Goldman, E.B., Monaco, J., Norgaard-Pedersen, B., et al. (2011) Committee Report: Considerations and Recommendations for National Guidance Regarding the Retention and Use of Residual Dried Blood Spot Specimens after Newborn Screening. Genetics in Medicine, 13, 621-624.

http://dx.doi.org/10.1097/GIM.0b013e3182147639 